\title{
Effects of Diallyl Disulfide in Elephant Garlic Extract on Breast Cancer Cell Apoptosis in Mitochondrial Pathway
}

\author{
Xin $\mathrm{An}^{1}$, Xiuhai Zhang ${ }^{2}$, Hongjun $\mathrm{Yao}^{1}$, Hongyang $\mathrm{Li}^{1}$, Jianwu Ren ${ }^{1, *}$ \\ ${ }^{1}$ Beijing Forestry University, College of Biological Sciences and Biotechnology, Beijing, P.R.China \\ ${ }^{2}$ Beijing Academy of Agriculture and Forestry Sciences, Beijing, P.R.China \\ *Corresponding author: jianwur@sina.com
}

Received March 10, 2015; Revised March 20, 2015; Accepted March 24, 2015

\begin{abstract}
As a close relative of garlic, elephant garlic contains abundant allicin, which means the extract of elephant garlic might induce apoptosis in breast cancer cells. The elephant garlic was extracted in alcohol with Solvent - Microwave Extraction. The main component was analyzed by liquid chromatography. The MCF-7 (michigan cancer foundation -7) cells were cultured in vitro. The apoptosis rate was determined with Annexin VFITC/PI staining based flow cytometry (FCM). Mitochondrial transmembrane potential variation in the cells was observed with JC-1 probe and fluorescence confocal microscopy. Caspase-3 was determined with fluorescence Western Blot. The main component of alcohol extract of elephant garlic was Diallyl Disulfide (DADS), and its relative content was $17.04 \%$. The early apoptosis of MCF-7 cells could be induced by the alcohol extract solutions and it involved the activation of mitochondrial pathway. The results indicated that the extract and DADS standards exerted pro-apoptotic effects on breast cancer cells in a dose-response manner. From the results of fluorescence confocal microscopy, it showed that the Red/Green fluorescence ratio of mitochondrial membrane potential in MCF7 cells could be significantly decreased after inducing with DADS reference substances for $24 \mathrm{~h}$. In addition, mitochondrial depolarization could be observed as adding the extract. The activated Caspase-3 was detected with Western Blot. It was demonstrated that the expression level of procaspase-3 had gone up with increased concentration of alcohol extract. The expression level was also increased with the treatment of DADS and the protein band was clear.
\end{abstract}

Keywords: caspase-3, cell apoptosis, Diallyl Disulfide (DADS), elephant garlic, mitochondrial transmembrane potential

Cite This Article: Xin An, Xiuhai Zhang, Hongjun Yao, Hongyang Li, and Jianwu Ren, "Effects of Diallyl Disulfide in Elephant Garlic Extract on Breast Cancer Cell Apoptosis in Mitochondrial Pathway.” Journal of Food and Nutrition Research, vol. 3, no. 3 (2015): 196-201. doi: 10.12691/jfnr-3-3-11.

\section{Introduction}

Garlic (Allium sativum L.) is one of the best-researched herbal remedies. It exhibits the capability of protecting the human body against a wide variety of diseases. Much health benefit related biological effects have been found in garlic. It has proved that the special effects of garlic were attributed to organosulfur compounds rich in garlic. Among these compounds, allicin has been best known and most extensively studied. In 1944, CJ Cavallito and coworkers have observed the extract of fresh garlic cloves could be antibacterial. They proved the antibacterial effects were resulted from the allicin in garlic. Compared with widely applied phytoncides, allicin was more stable and less volatile. [1] In following studies, Cavallito's group has firstly determined the chemical structures of allicin. The allicin has been proved to be a mixture of many allyl sulfides. It was composed of $50 \%$ to $80 \%$ diallyl trisulfide (DATS), $20 \%$ to $50 \%$ diallyl disulfide (DADS) and $8 \%$ of other impurities (such as acetone, ethanol and so on).
Many health related effects have been observed in allicin, including antibacterial, antiseptic, antioxidant, lowering the blood pressure and blood fat, as well as preventing from cardiovascular diseases such as atherosclerosis. [2,3] Specifically, allicin in its pure form has been observed to exhibit i) antibacterial activity against a wide range of Gram-negative and Gram-positive bacteria; ii) antifungal activity, particularly against Candida albicans; iii) antiparasitic activity, including some major human intestinal protozoan parasites; and iv) antiviral activity.

Therefore, a plenty of studies have been performed to explore the specific biological activities and mechanism of these effects, including anti-microbial, anti-tumor, antifungal and immune-modulatory. [4,5,6,7] The main antimicrobial effect of allicin is due to its chemical reaction with thiol groups of various enzymes. Using PC-3 (human prostate cancer cell lines) and DU145 (human prostate cancer cell lines) as a model, Dong Xiao et al. found that DATS was a significantly more potent apoptosis inducer than diallyl sulfide (DAS) or diallyl disulfide (DADS). Tooba Ghazanfari has showed that peritoneal macrophage phagocytic activity against 
Leishmania major could be enhanced by garlic (Allium sativum) treatment [8].

As the main effective ingredient in garlic, allyl sulfides have attracted more attentions from scientists. The researches have mainly focused on the anti-tumor activities and related mechanism. Epidemiological and experimental studies at home and abroad showed that a variety of tumors could be significantly inhibited by allyl sulfides, including stomach cancer, colon cancer, liver cancer, lung cancer, prostate cancer, breast cancer and leukemia etc. $[9,10]$ Oommen $\mathrm{S}$ has explored that Caspase-3, Caspase-8 and Caspase-9 in tumor cells could be activated by allicin and poly (ADP-ri2bose) polymerase could be degraded with the effects of allicin. [11] There was also study on apoptotic response of human breast cancer cells to allicin. For human breast cancer cells, cell proliferation in MDA-MB-231 (human breast cancer cell lines) cells could be decreased by allicin in concentration-dependent manner. In MDA-MB-231 cells, cell growth was inhibited and apoptosis was induced through MAPKs (mitogen-activated protein kinases) and ER (estrogen receptor) signaling pathways. [12] In their further study on the apoptotic effect of allicin in MCF-7 cells, another human breast cancer cells. The data suggested that apoptosis was induced by allicin through MAPKs and ATF3 (cyclic AMP-dependent transcription factor) signaling pathways in MCF-7 cells [13].

However, elephant garlic (Allium ampeloprasum), a close relative of garlic with very large cloves, tender flavor and abundant allicin. [14,15] Although the elephant garlic has been larger than garlic in volume, its flavor is tender and more acceptable for some people not like garlic. The allicin content was also varied in different species. Analysis of thiosulfinates from various Allium sp. revealed a 3-fold order of magnitude variation among species. Common garlic (A. sativum) and wild garlic had the highest levels, while elephant garlic (A. ampeloprasum) and Chinese chives have intermediary levels. Environmental conditions were also found to affect the total thiosulfinate levels. As an important specie of garlic, much less attentions have been paid on the anti-tumor effects of elephant garlic. In this study, it mainly explored the effects of alcohol extract of elephant garlic on MCF-7 tumor cells. It aimed to reveal the drug induced early apoptosis in breast cancer cells, as well as the mitochondrial pathway in apoptosis induction mechanism.

\section{Materials and Methods}

\subsection{Subjects}

Elephant garlic was provided by Agricultural Biotechnology Center, Beijing Academy of Agriculture and Forestry Sciences. MCF-7 breast cancer cells were purchased from cell resource center in School of Basic Medicine, Peking Union Medical College. MCF-7 cells were cultured in 1640 medium containing $10 \%$ fetal bovine serum, $1 \%$ penicillin and $1 \%$ streptomycin. The cells were incubated in $37^{\circ} \mathrm{C}, 5 \%$ carbon dioxide incubator. Annexin V-FITC/PI kit, JC-1 kit and Protein cell lysis solution were purchased from Applygen Technologies Inc. 2* reaction solution, 6* Protein Loading Buffer, molecular markers marker, NC membrane

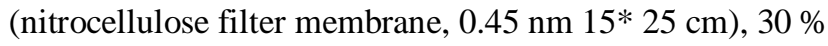
polyacrylamide solution, Tris $\mathrm{HCl}$ 8.8, APS ammonium persulfate solution, Tris $\mathrm{HCl}$ 6.8, ECL substrate, electrical transferring solution, $10^{*}$ blocking washing buffer, separating gel buffer, spacer gel buffer, TEMED, imported skimmed milk powder, DADS reference substance, methanol were all obtained from Applygen Technologies Inc. The water was sterile distilled water. Other involved instruments were aseptic clean biological safety cabinet, automatic electric pressure steam sterilizer, cell incubator (BC-J80S), centrifuges, BD flow cytometery (BD Vantage $\mathrm{SE})$, electrophoresis, electrophoresis tank, confocal microscopy (XSP-63XDV), vortex shaker, ZQ24000/2695 quadrupole LC / MS spectrometer (Waters, USA) and 2695 high-performance liquid chromatography.

\subsection{Preparation of Crude Elephant Garlic Extract and Standard Solutions}

The elephant garlic was extracted with alcohol by solvent-microwave extraction. The method was previously reported by Qiao et al. and He et al. [16,17] The elephant garlic was peeled and mashed with Plant tissue triturator for $20 \mathrm{~min}$. The mashed garlic was prepared. $2 \mathrm{~g}, 4 \mathrm{~g}$ and $8 \mathrm{~g}$ mashed garlic was weighed (with the accuracy of $0.001 \mathrm{~g}$ ). 3 samples were placed in water bath of $40^{\circ} \mathrm{C}$ and kept still for 0.5 h. $95 \%$ alcohol was added in mashed garlic samples with the solid-liquid ratio of 1:4 $\left(\mathrm{g} \mathrm{ml}^{-1}\right)$. The mixture was extracted for $2 \mathrm{~h}$ in microwave oscillator at $30^{\circ} \mathrm{C}$. The supernatant was separated and concentrated with rotary evaporation at $50^{\circ} \mathrm{C}$ with speed of $75 \mathrm{r} \mathrm{min}^{-1}$. After ethanol evaporated, the crude extract of elephant garlic was collected. The allicin content was determined with spectrophotometric method. [18] The solutions of allicin extract was filtered by sterilized filter. After filtration, the solution was diluted with 1640 medium with a final concentration of $100 \mathrm{ul} 10 \mathrm{ml}^{-1}$. The solutions were stored at $4^{\circ} \mathrm{C}$. Three parallel experiment analyses are carried out.

$7.62 \mathrm{mg}$ DADS reference substance was accurately weighed and dissolved with methanol (high performance liquid chromatography/HPLC grade). The methanol was added to volume of $25 \mathrm{~mL}$ volumetric flask. After shaking, the uniform solution was taken as stock solution of reference substance.

\subsection{Chromatographic Conditions}

The gradient elution was carried out with methanol and water. The column was Waters Symmetry C18 (3.9 mm × $150 \mathrm{~mm}, 5 \mu \mathrm{m})$ column. The flow rate of mobile phase was $0.5 \mathrm{~mL} \mathrm{~min} \mathrm{~m}^{-1}$. The good separation efficient could be realized at $30 \mathrm{~min}$. Three parallel experiment analyses are carried out.

Column: Waters Symmetry C18 column (3.9 mm*150 $\mathrm{mm}, 5 \mu \mathrm{m})$. Mobile phase: methanol, water. Elution gradient of methanol: $60 \%$ to $100 \%$ (0 to $10 \mathrm{~min}$ ); $100 \%$ (10 to $20 \mathrm{~min}$ ); $100 \%$ to $60 \%$ (20 to $25 \mathrm{~min}$ ); $60 \%$ (25 to $30 \mathrm{~min})$. Flow rate: $0.5 \mathrm{~mL} \mathrm{~min}^{-1}$. Column temperature: $30^{\circ} \mathrm{C}$. Detection wavelength: $254 \mathrm{~nm}$.

\subsection{Apoptosis Analysis with Annexin V- FITC/PI Staining Based Flow Cytometry}


The MCF-7 cells in logarithmic phase were passaged. The cells were counted and seeded in 6-well cell culture plate. The cell concentration was $10^{5} \mathrm{~mL}^{-1}$ with $2 \mathrm{~mL}$ cells per well and cultured overnight for cell adhesion. There were blank control group and experiment groups. Three parallel experiment analyses are carried out. In blank control group, 1640 medium was added. In experiment groups, 1640 medium with different concentrations of allicin was added. After incubating for $24 \mathrm{~h}$, following procedures were carried out according to the instruction of Annexin V-FITC/PI kit. The culture medium was discarded and the cells were washed twice with PBS (phosphate buffered saline) at $4^{\circ} \mathrm{C}$. The cells were trypsinized to prepare single cell suspension. After centrifuging and washing, the cells were re-suspended with blind buffer, with a final concentration of $10^{6}$ per ml. $100 \mathrm{ul}$ cells were suspended in $5 \mathrm{~mL}$ streaming tube and 5ul Annexin V-FITC solution was added and kept still for 5 min. $10 \mu \mathrm{l}$ PI (propidium iodide) with the concentration of $20 \mu \mathrm{g} \mathrm{ml}^{-1}$ was mixed with above solutions and stayed at room temperature away from light for $15 \mathrm{~min}$. $500 \mu \mathrm{L}$ blinding buffer was added before detecting cell apoptosis with flow cytometry.

\subsection{Determination of Mitochondrial Membrane Potential}

The MCF-7 cells in logarithmic phase were passaged and then plated in confocal Petri dish with concentration of $10^{5}$ per $\mathrm{mL}$. The cells were cultured overnight. There were blank control group and experiment groups. Three parallel experiment analyses are carried out. In blank control group, 1640 medium was added. In experiment groups, 1640 medium with different concentrations of allicin was added. After $24 \mathrm{~h}$, following procedures were carried out according to the instruction of JC-1 kit. The culture medium was discarded and the cells were washed twice with PBS at $4^{\circ} \mathrm{C}$. JC- 1 solution with final concentration of $2.5 \mu \mathrm{g} \mathrm{ml}^{-1}$ was added and incubated for $30 \mathrm{~min}$ in incubator. The cells were stained and washed with PBS. After discarding PBS washing buffer, the cell culture medium was added. The results were observed with confocal microscopy.

\subsection{Expression Analysis of Caspase-3 Protein with Western Blot}

The MCF-7 cells in logarithmic phase were passaged. The cells were counted and seeded in 6-well cell culture plate. The cell concentration was $10^{5} \mathrm{~mL}^{-1}$ with $5 \mathrm{~mL}$ cells per well and cultured overnight for cell adhesion. There were blank control group and experiment groups. Three parallel experiment analyses are carried out. In blank control group, 1640 medium was added. In experiment groups, 1640 medium with different concentrations of allicin was added. After incubating for $24 \mathrm{~h}$, the culture medium was discarded and the cells were washed twice with PBS at $4^{\circ} \mathrm{C}$. The cells were trypsinized to prepare single cell suspension. The cells were washed once with PBS. After discarding the supernatant, lysis solution was added (50 $\mu \mathrm{L}$ lysis solution per 2 million cells). The deposition was re-suspended and lysed for $30 \mathrm{~min}$ in ice bath. During this period, the solutions were vortexed for 3-4 times, $10 \mathrm{~s}$ per time. Then the solutions were centrifuged for $10 \mathrm{~min}$ at $12000 \mathrm{r} \mathrm{min}^{-1}$. The supernatant was carefully disposed and placed in $1 \mathrm{ml}$ centrifuge tube. $6 *$ loading buffer was added. The solution was boiled at $100^{\circ} \mathrm{C}$ and stored at $-20^{\circ} \mathrm{C}$ for use.

The separation gel and spacer gel for $12 \%$ SDS-PAGE (sodium dodecyl sulfate polyacrylamide gel electrophoresis) were prepared according to the ratio of the table. The gel was stored at $4^{\circ} \mathrm{C}$ for further uses. In the electrophoresis, the marker and different samples of protein solutions were injected into the slots of gel. After accessing to power, the voltage was adjusted. After electrophoresis for $2 \mathrm{~h}$, the glass plates were removed. The spacer gel was disposed and the separation gel was cut into appropriate size. The NC membrane and sponge was added and wet-transferred for $2 \mathrm{~h}$. The $1^{\text {st }}$ antibody was added and then the membrane was blocked overnight at $4^{\circ} \mathrm{C}$. The NC membrane was washed three times, 5 min each time. The NC membrane was incubated with $2^{\text {nd }}$ antibody at room temperature for 2h. The substrate was added after washing.

\section{Results and Analysis}

\subsection{Maximum Absorption Peak and Chromatogram of Allicin in Elephant Garlic}

The crude extract solution of elephant garlic was analyzed with liquid chromatography. The main component in crude extract of elephant garlic was diallyl disulfide (DADS) (Table 1 and Figure 1). The maximum adsorption peak was at $254 \mathrm{~nm}$. As the main component, DADS was separated from crude extract of elephant garlic with liquid chromatography. The peak area was 17.03516.

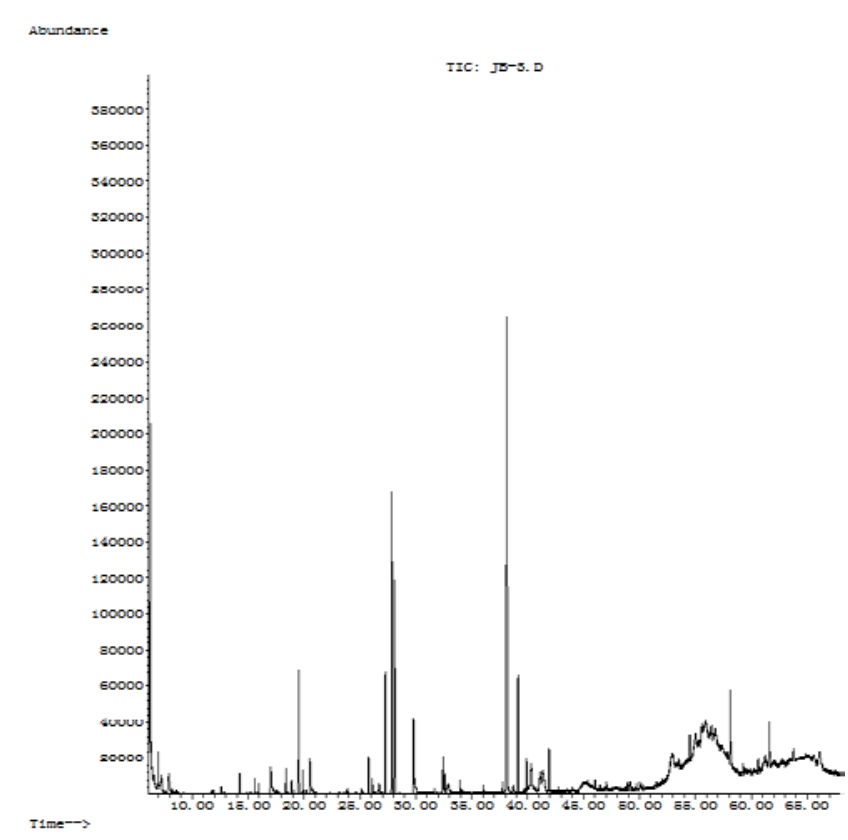

Figure 1. The chromatogram of crude extract solution of elephant garlic

\subsection{The Effects of DADS and Elephant Garlic Crude Extract On Early Apoptosis Rate of MCF-7}

Both the DADS reference substance and elephant garlic crude extract have made effects on the apoptosis of MCF7. The effects were detected by flow cytometry with 
Annexin V-FITC/PI double staining flow cytometry. In the analysis of apoptosis, there was apoptosis happened to MCF-7 breast cancer cells after treatment for $24 \mathrm{~h}$ with different concentrations of crude extract solutions. It suggested the pro-apoptotic effect of crude extract solution was made in a dose-response manner. In the treatment of DADS, the early apoptosis could also happen to MCF-7 cell in an identical proportion. With the increased concentration of crude extracts, the early apoptosis rates were $11.57 \%, 18.69 \%$ and $26.98 \%$, respectively (Figure 2). The results demonstrated that breast cancer cells could be significantly induced by crude extract solution of elephant garlic. The diallyl disulfide, as the main component of crude extract solution, could perform anti-tumor effects.

Table 1. Components analysis of crude extract solution of elephant garlic

\begin{tabular}{|c|c|c|c|}
\hline $\mathrm{PK}$ & RT & Area Pct & Library/ID \\
\hline 1 & 6.24 & $6.36 \pm 0.72$ & Cyclohexane, methyl- \\
\hline 2 & 6.30 & $0.14 \pm 0.04$ & Cyclopentane, ethyl- \\
\hline 3 & 6.97 & $1.05 \pm 0.13$ & Norbornane \\
\hline 4 & 7.92 & $1.83 \pm 0.09$ & Thiirane, methyl- \\
\hline 5 & 14.25 & $0.60 \pm 0.02$ & 1-Propene, 3,3'-thiobis- \\
\hline 6 & 15.61 & $0.44 \pm 0.07$ & 1-Propene, 1,1'-thiobis- \\
\hline 7 & 17.03 & $1.15 \pm 0.12$ & Thiacyclobutane-3-ol \\
\hline 8 & 18.38 & $0.87 \pm 0.09$ & 3,4-Dimethylthiophene \\
\hline 9 & 18.88 & $0.40 \pm 0.05$ & Thiophene, 2,5-difluoro- \\
\hline 10 & 19.53 & $4.63 \pm 0.56$ & Disulfide, methyl 2-propenyl \\
\hline 11 & 19.89 & $0.76 \pm 0.08$ & 1,3-Dithiane \\
\hline 12 & 20.53 & $1.68 \pm 0.19$ & N-Methyl-7-azabicyclo(2,2,1)hept-2-ene \\
\hline 13 & 25.76 & $1.31 \pm 0.14$ & Ethene, 1,2-bis(ethylthio)- \\
\hline 14 & 26.11 & $0.50 \pm 0.06$ & Cyclohexanone, 2,2,5,5-tetramethyl-3-methylene- \\
\hline 15 & 27.26 & $4.66 \pm 0.51$ & Diallyl disulphide \\
\hline 16 & 27.86 & $12.38 \pm 1.32$ & Diallyl disulphide \\
\hline 17 & 28.10 & $8.48 \pm 0.92$ & 1-Oxa-4,6-diazacyclooctane-5-thione \\
\hline 18 & 29.79 & $2.75 \pm 0.53$ & Thiourea, ethyl- \\
\hline 19 & 32.44 & $1.52 \pm 0.18$ & Methyl(methyl 4-O-methyl-.alpha.-d-mannopyranoside)uronate \\
\hline 20 & 32.59 & $0.81 \pm 0.12$ & Thiophene, 2-chloro- \\
\hline 21 & 38.14 & $26.01 \pm 1.94$ & 3-Vinyl-1,2-dithiocyclohex-4-ene \\
\hline 22 & 39.13 & $5.12 \pm 0.66$ & Crotonic acid, 4-mercapto-3-(methylthio)-, gamma.-(thio lactone) \\
\hline 23 & 39.91 & $1.27 \pm 0.22$ & Trisulfide, di-2-propenyl \\
\hline 24 & 40.31 & $2.85 \pm 0.19$ & Anhydro-1,6-dimethyl-5-hydroxyimidazo-[2,1-b][1,3]-thiazine-7-one hydroxide \\
\hline 25 & 41.10 & $0.91 \pm 0.11$ & Ethanone, 1-(3-methylenecyclopentyl)- \\
\hline 26 & 41.35 & $0.90 \pm 0.08$ & Benzene, diethenyl- \\
\hline 27 & 41.92 & $1.81 \pm 0.24$ & 3-Vinyl-1,2-dithiocyclohex-5-ene \\
\hline 28 & 52.84 & $0.11 \pm 0.02$ & n-Hexadecanoic acid \\
\hline 29 & 52.88 & $0.02 \pm 0.01$ & n-Hexadecanoic acid \\
\hline 30 & 54.50 & $0.95 \pm 0.16$ & Hexadecanoic acid, ethyl ester \\
\hline 31 & 54.99 & $0.90 \pm 0.15$ & 2(1H)Naphthalenone, 3,5,6,7,8,8a-hexahydro-4,8a-dimethyl-6-(1-methylethenyl)- \\
\hline 32 & 55.03 & $0.19 \pm 0.03$ & $\begin{array}{l}\text { 2H-Cyclopropa[a]naphthalen-2-one, } \quad \text { 1,1a,4,5,6,7,7a,7b-octahydro-1,1,7,7a- } \\
\text { tetramethyl-, (1a.alpha.,7.alpha.,7a.alpha.,7b.alpha.)- }\end{array}$ \\
\hline 33 & 55.54 & $0.17 \pm 0.02$ & 2(1H)Naphthalenone, 3,5,6,7,8,8a-hexahydro-4,8a-dimethyl-6-(1-methylethenyl)- \\
\hline 34 & 55.56 & $0.20 \pm 0.05$ & 2(1H)Naphthalenone, 3,5,6,7,8,8a-hexahydro-4,8a-dimethyl-6-(1-methylethenyl)- \\
\hline 35 & 58.11 & $3.26 \pm 0.38$ & Naphthalene, 2,3,6-trimethyl- \\
\hline 36 & 60.63 & $0.66 \pm 0.09$ & 2-Nonadecanol \\
\hline 37 & 61.62 & $1.92 \pm 0.24$ & Linoleic acid ethyl ester \\
\hline
\end{tabular}

All values of Area Pct are expressed as means \pm SE.

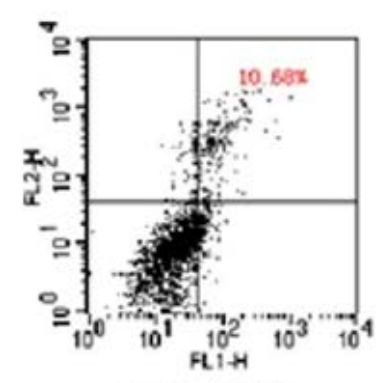

A (DADS)

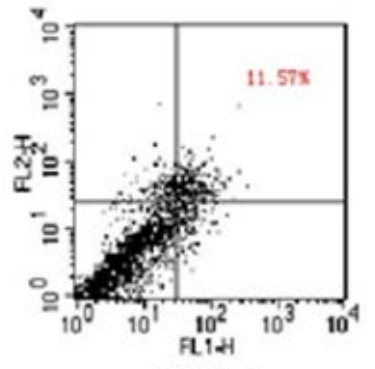

$\mathrm{B}(2 \mathrm{~g})$

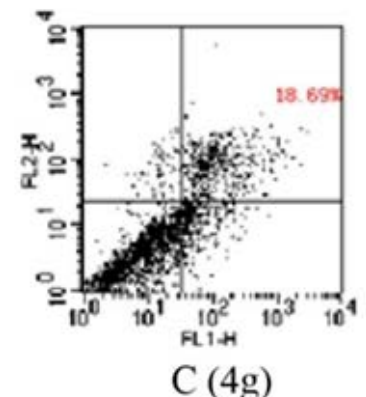

$\mathrm{C}(4 \mathrm{~g})$

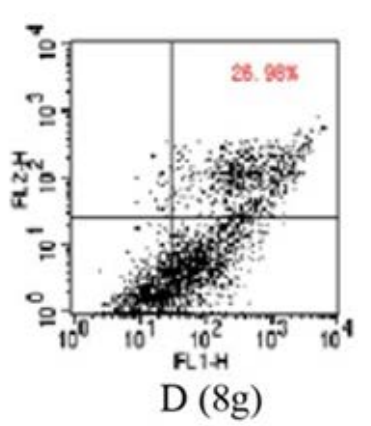

Figure 2. Early apoptosis analysis with flow cytometry

\subsection{The Mitochondrial Depolarization Induced by DADS and Elephant Garlic Crude Extract}

The early events in pro-apoptosis effects of DADS on breast cancer cells have been explored. The effects of crude extract on mitochondrial depolarization in MCF-7 were determined with JC-1 probe and fluorescence confocal microscopy. The results showed that the depolarization was observed in cells treated with DADS. For crude extract of elephant garlic, the mitochondrial membrane potential would be decreased after treating for $24 \mathrm{~h}$ and the depolarization was observed. It performed as decreased ratio of red/green fluorescence (Figure 3). There was also a dose-response relationship. The results suggested that mitochondrial depolarization could be 
induced by DADS in breast cancer cells. Thus, the cell apoptosis could be triggered.

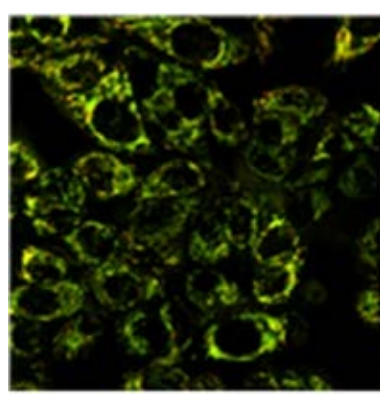

A (DADS)

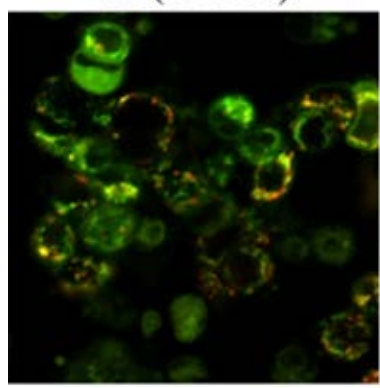

C ( $(4 \mathrm{~g})$

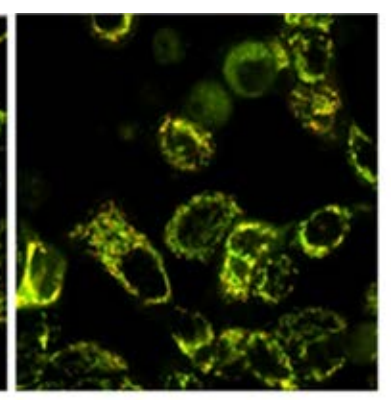

B (2g)

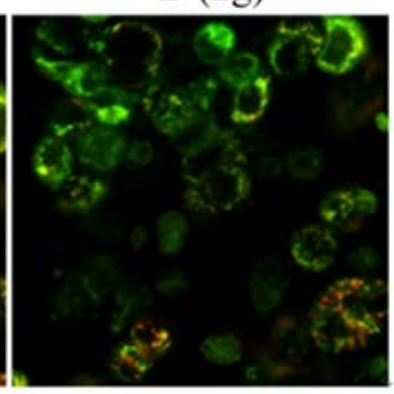

D $(8 \mathrm{~g})$
Figure 3. The effects of DADS on the mitochondrial depolarization in breast cancer cells

\subsection{The Expression Level of Procaspase-3 in MCF-7 after Induction}

The MCF-7 cells were treated with different concentrations of elephant garlic crude extract and DADS, respectively. After $24 \mathrm{~h}$, the total cell protein was lysed for performing Western Blot. From the results, the activated procaspase was observed in DADS treated cells. For crude extract treated group, the bands of procaspase (32 KD) and large subunit (17 KD) could be clearly observed, indicating apoptosis in cells. The results indicated that cell apoptosis could be promoted by DADS, the main component of elephant garlic crude extract. The protein expression of apoptotic gene caspase-3 could be clearly observed (Figure 4).

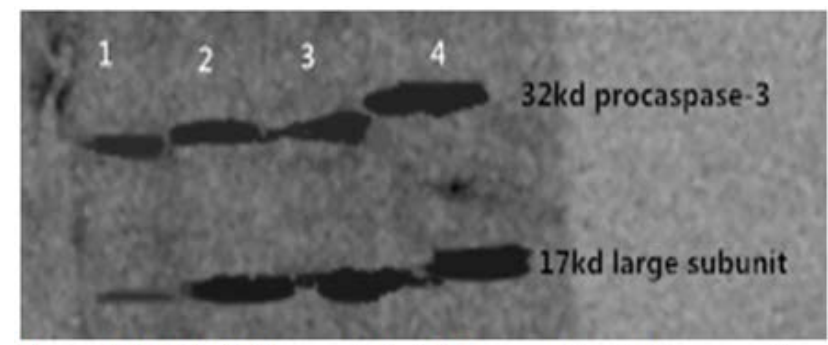

Notes: 1.DADS, 2. Dosage of $2 \mathrm{~g}, 3$. Dosage of $4 \mathrm{~g}, 4$. Dosage of $8 \mathrm{~g}$

Figure 4. The Western Blot analysis of activated procaspase-3

\section{Discussion}

Apoptosis is triggered by environment changes or death signals. It has been an active cell death program under the gene regulation. Most of people believed that cancer was due to excessive cell proliferation and insufficient cell apoptosis. In the treatment or induction of tumor cells, the cell proliferation has been generally inhibited, as well as inducing early cell apoptosis [19,20].

Three major pathways of cell apoptosis are death receptor mediated apoptosis pathway or extrinsic pathways, mitochondrial apoptotic pathway or the intrinsic pathway and the endoplasmic reticulum pathway. Caspase family plays vital roles in mediating apoptosis. Wherein, Caspase-3 has been a key implementation molecule. It has made effects on many pathways related to apoptosis signal transduction. Generally, Caspase-3 existed in cytoplasm in the form of plasminogen (32 KD). In early stage of apoptosis, it was activated. The activated Caspase-3 is composed of two large subunits (17 KD) and two small subunits (12 KD). The corresponding cytoplasmic and nuclear substrates would be lysed, resulting in cell apoptosis. In this study, it focused on the mitochondrial pathway. The results have proved that the early apoptosis in MCF-7 cells would be induced by DADS. The mitochondrial depolarization was observed and it was an important performance of early apoptosis. The MCF-7 cells were activated by procaspse-3 in dose dependent manner.

Mitochondrial permeability transition pore (PT) is multi-protein complex located between inner and outer membrane of mitochondria. It plays an important role in regulating apoptosis. When the cell apoptosis is stimulated by various factors, the permeability of mitochondrial membrane would be increased. Many proteins in mitochondria would be released, including Cytochrome C. The Cytochrome $\mathrm{C}$ would be translocated into cytoplasm. The apoptotic body is formed by Cytochrome C, apoptosis activating factor Apaf-1 and Caspase-9 precursor. With the co-action of apoptotic body and dATP in cytoplasm, the Caspase- 9 would be activated. Other caspase including Caspase- 3 etc could be activated by activated Caspase- 9 . Then the DNA fragmentation factor would also be activated by Caspase-3, resulting in the activation of nucleic acid enzyme in resting state. It finally causes DNA breakage and damage [21].

The function integrity of mitochondrial membrane would be damaged in the high metabolic tumor cells. Thus, these cells would be more sensitive to apoptotic stimuli of mitochondrial apoptotic pathway. There have been drugs for cancers specific to the effective targets in mitochondria. [10] In this study, it proposed a target specific to mitochondria in MCF-7 tumor cell for cancer drugs. The results provided laboratory basis and reference for developing and studying drugs with relatively selectivity in cancers treatment.

\section{Conclusions}

The main component of alcohol extract of elephant garlic was Diallyl Disulfide (DADS). The early apoptosis of MCF-7 cells could be induced by the alcohol extract solutions and it involved the activation of mitochondrial pathway.

\section{Acknowledgement}

We thank Dr. Yujie Shi with Peiking University Health Science Center for her kind help and suggestions in data analysis. 


\section{References}

[1] Nwachukwu, I.D., and Asawalam, E.F., "Evaluation of freshly prepared juice from garlic (Allium sativum L.) as a biopesticide against the maize weevil, Sitophilus zeamais (Motsch.) (Coleoptera: Curculionidae)," Journal of Plant Protection Research, 54 (2). 132-138. Jul.2014.

[2] Nkrumah-Elie, Y.M., Reuben, J.S., Hudson, A., Taka, E., Badisa, R., Ardley, T., and et al, "Diallyl trisulfide as an inhibitor of benzo(a)pyrene-induced precancerous carcinogenesis in MCF10A cells," Food and Chemical Toxicology, 50 (7). 2524-2530. Apr.2012.

[3] Sengupta, A., Ghosh, S., and Bhattacharjee, S., "Allium vegetables in cancer prevention: an overview," Asian Pacific Journal of Cancer Prevention, 5 (3). 237-245. Jul.2004.

[4] Cutler, R.R., and Wilson, P., "Antibacterial activity of a new, stable, aqueous extract of allicin against methicillin-resistant Staphylococcus aureus," British Journal of Biomedical Science, 61 (2). 71-74. Mar.2004.

[5] Park, S.Y., Cho, S.J., Kwon, H.C., Lee, K.R., Rhee, D.K., and Pyo, S., "Caspase-independent cell death by allicin in human epithelial carcinoma cells: involvement of PKA," Cancer Letters, 224 (1). 123-132. Jun.2005.

[6] Davis, S.R., "An overview of the antifungal properties of allicin and its breakdown products-the possibility of a safe and effective antifungal prophylactic,” Mycoses, 48 (2). 95-100. Mar.2005.

[7] Lang, A., Lahav, M., Sakhnini, E., and et al, "Allicin inhibits spontaneous and TNF-alpha induced secretion of proinflammatory cytokines and chemokines from intestinal epithelial cells," Clinical Nutrition, 23 (5). 1199-1208. Oct.2004.

[8] Ghazanfari, T., Hassan, Z.M., and Khamesipour, A., "Enhancement of peritoneal macrophage phagocytic activity against Leishmania major by garlic (Allium Sativum) treatment,” Journal of Ethnopharmacology, 103 (3). 333-337. Feb.2006.

[9] Galeone, C., Pelucchi, C., Levi, F., and et al, "Onion and garlic use and human cancer," The American Journal of Clinical Nutrition, 84 (5). 1027-1032. Nov.2006.

[10] Wang, F., Ogansawara, M.A., and Huang, P., "Small mitochondria targeting molecules as anti-cancer agents," Molecular Aspects of Medicine, 31 (1). 75-92. Dec.2009.

[11] Oommen, S., Anto, R.J., Srinivas, G., and Karunagaran, D., "Allicin (from garlic) induces caspase-mediated apoptosis in cancer cells,” European Journal of Pharmacology, 485 (1-3). 97103. Feb.2004.

[12] Kim, K., Rhee, D.K., and Pyo, S., "Differential apoptotic response of human breast cancer cells to allicin," Faseb Journal, 25. 612.3. Mar.2011.

[13] Park, B., Kim, K., Rhee, D.K., and et al, "The apoptotic effect of allicin in MCF-7 human breast cancer cells: role for ATF3,” Faseb Journal, 26. lb367. Mar.2012.

[14] Pongsak, R., and Parichat,P., "Antimicrobial activity of elephant garlic oil against vibrio cholerae in vitro and in a food model," Bioscience Biotechnology and Biochemistry, 73 (7). 1623-1627. Apr.2009.

[15] Eric Block, John, A. D., and Robert, B.C., "Crushing Garlic and Slicing Onions: Detection of Sulfenic Acids and Other Reactive Organosulfur Intermediates from Garlic and Other Alliums using Direct Analysis in Real-Time Mass Spectrometry (DART-MS)," Phosphorus Sulfur and Silicon and the Related Elements, 186(5). 1085-1093. Jul.2011.

[16] Qiao, A.X., Kang, L.M., Zhi, X.X., and Pan, J.G., "Optimum extraction of allicin from Allium sativum L. and its mathematical model," Guangdong Agricultural Sciences, 20. 101-104. 2013.

[17] He, L., Gu, Y., Liu, G.Z., Wang, Q.Z., Yan, S.L., and Li, J., "Optimization of ultrasound-assisted extraction of allicin using response surface methodology,” Food Science, 34 (6). 98-101. Mar.2013.

[18] Pirak, T., Jangchud, A., and Jantawat, P., "Characterisation of physical, chemical and antimicrobial properties of allicin chitosan complexes," International Journal of Food Science and Technology, 47 (7). 1339-1347. Jul.2012.

[19] Rouhani, M., Goliaei, B., Khodagholi, F., and Nikoofar, A., "Lithium increases radiosensitivity by abrogating DNA repair in breast cancer spheroid culture," Archives of Iranian Medicine, 17 (5). 352- 360. May.2014.

[20] Kumar, C.K., Lee, J., and Shivendra, V.S., "Critical role for reactive oxygen species in apoptosis induction and cell migration inhibition by diallyl trisulfide, a cancer chemopreventive component of garlic," Breast Cancer Research and Treatment, 138 (1). 69-79. Feb.2013.

[21] Sireesha, V.G., Kristie, G., Jennifer, L.D., and et al, "Identification of novel molecular regulators of tumor necrosis factor-related apoptosis-inducing ligand (TRAIL)-induced apoptosis in breast cancer cells by RNAi screening,” Breast Cancer Research, 16 (2). R41. Apr.2014. 